Submitted to Scripta Materialia in June 2016, Revised in July 2016

\title{
Effect of grain size on the superelastic response of a FeMnAINi polycrystalline shape memory alloy
}

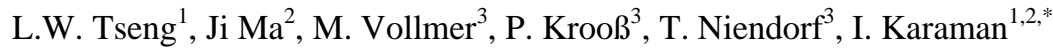 \\ ${ }^{1}$ Department of Mechanical Engineering, Texas A\&M University, MS 3123, College Station, TX 77843, USA \\ ${ }^{2}$ Department of Materials Science and Engineering, Texas A\&M University, College Station, TX 77843, USA \\ ${ }^{3}$ Institut für Werkstofftechnik (Materials Engineering), Universität Kassel, 34125 Kassel, Germany \\ *: Corresponding Author, ikaraman@tamu.edu
}

\begin{abstract}
The effect of heat treatments on superelasticity was investigated in a FeMnAlNi polycrystalline alloy using incremental tensile strain tests at room temperature. Large grains of more than several centimeters can be obtained by a cyclic heat treatment process and the average grain size can be controlled by the number of heat treatment cycles. Improved superelastic response is observed in samples with large relative grain sizes, exhibiting increased elongation to fracture, lower critical stress for transformation, and higher reversibility.
\end{abstract}

Keywords: FeMnAlNi; Fe-based shape memory alloys, Superelasticity; Abnormal grain growth; Microstructure 
Common superelastic materials recover large applied strains after unloading due to reversible stress-induced martensitic phase transformation. NiTi -based shape memory alloys (SMAs) are commonly used in industrial applications because of high superelastic strains up to $8 \%$; however, high material costs and poor cold-workability have limited their wide spread use in industrial applications. By comparison, Fe-based SMAs attracted a lot of attention over the last few decades due to low material cost and outstanding cold-workability. However, the superelastic properties of most Fe-based SMAs, in terms of the level of transformation strains and shape recovery are poor [1-6].

In 2010, Tanaka et al. [7] reported that addition of Ta and B into the FeNiCoAl alloy system changes the martensitic transformation from non-thermoelastic to thermoelastic resulting in excellent superelasticity up to $13.5 \%$ strain in a $\mathrm{Fe}_{40.95} \mathrm{Ni}_{28} \mathrm{Co}_{17} \mathrm{Al}_{11.5} \mathrm{Ta}_{2.5} \mathrm{~B}_{0.05}$ SMA. Since then several similar alloy systems such as $\mathrm{Fe}_{40.95} \mathrm{Ni}_{28} \mathrm{Co}_{17} \mathrm{Al}_{11.5} \mathrm{Ti}_{2.5} \mathrm{~B}_{0.05}$ [8], $\mathrm{Fe}_{40.95} \mathrm{Ni}_{28} \mathrm{Co}_{17} \mathrm{Al}_{11.5} \mathrm{Nb}_{2.5} \mathrm{~B}_{0.05}$ [9], $\mathrm{Fe}_{41} \mathrm{Ni}_{28} \mathrm{Co}_{17} \mathrm{Al}_{11.5} \mathrm{Ta}_{2.5}$ [10-13], $\mathrm{Fe}_{41} \mathrm{Ni}_{28} \mathrm{Co}_{17} \mathrm{Al}_{11.5} \mathrm{Ti}_{2.5}$ $[14,15]$ and $\mathrm{Fe}_{41} \mathrm{Ni}_{28} \mathrm{Co}_{17} \mathrm{Al}_{11.5} \mathrm{Nb}_{2.5}$ [16] have been reported showing up to 5-6\% superelastic strain at room temperature.

In 2011, Omori et al. [17] reported thermoelastic martensitic transformation in FeMnAl alloys after the addition of $\mathrm{Ni}$ and formation of high volume fraction of very small (3-5 nm) nano-precipitates. $\mathrm{Fe}_{43.5} \mathrm{Mn}_{34} \mathrm{Al}_{15} \mathrm{Ni}_{7.5}$ alloy demonstrated up to 5\% superelastic strain in both single crystalline and polycrystalline conditions [18-23]. Probably the most interesting characteristic behavior of this material is the small temperature dependence of the critical stress for stress-induced martensitic transformation [17]. This means that the required stress to trigger superelasticity does not change appreciably with temperature, and a large superelastic temperature window from $-196^{\circ} \mathrm{C}$ to $240^{\circ} \mathrm{C}$ is possible.

In NiTi alloys, the incompatibility between grains upon martensitic transformation is easily accommodated by the formation of corresponding variant pairs (CVP) involving two or 
four variants during deformation. This is due to twenty-four martensite variants which can theoretically be activated during B2 to B19' martensitic transformation [24]. Therefore, large grain size is not required to obtain superelastic behavior in NiTi and similar SMAs [24]. Unlike NiTi alloys, only three martensite variants can be activated in FCC to BCT transformation of Fe-based SMAs $[10,11,19,23]$, therefore the grain boundary incompatibility cannot be easily accommodated as the Taylor criterion for generalized deformation is not satisfied. Related to this, the superelastic properties strongly depend on the average grain size (d) relative to the thickness (t) or diameter (D) of the test sample. For example, FeNiCoAlTaB polycrystals with large mean relative grain size $(\mathrm{d} / \mathrm{t}=400 \mu \mathrm{m} / 220 \mu \mathrm{m})$, about 1.8, were reported to show over $13 \%$ recoverable strain [7]. In FeMnAlNi polycrystalline sheets and wires, 5\% recoverable strain was obtained with relative grain size about 15 in sheets [17] and 2.19 in wires [18]. Although the $\mathrm{d} / \mathrm{t}$ ratio of FeMnAlNi polycrystal is comparable to that in a single crystal, the gage section of the samples is nevertheless made up of multiple grains. The texture intensity in the polycrystal is weak [17] and some grains are oriented near the $<100>$ direction. From the FeMnAlNi single crystal studies, samples along the $\langle 100\rangle$ orientation shows poor reversibility in tension [23]. As such, the superelastic response of the bamboo-like polycrystal samples is worse compared to favorably-oriented single crystals such as $\langle 110\rangle$, but better compared to unfavorably-oriented single crystals such as $<100>$. In the present study, the effect of grain size on the characteristics of superelasticity such as critical stress, superelastic strain, elongation and fracture in FeMnAlNi polycrystalline alloys with two different average grain sizes are investigated, and a thermomechanical treatment by which grain size can be controlled is proposed.

As-cast $\mathrm{Fe}_{43.5} \mathrm{Mn}_{34} \mathrm{Al}_{15} \mathrm{Ni}_{7.5}$ (at.\%) ingots were thermo-mechanically processed to obtain polycrystalline sheets following the procedures mentioned below:

(1) hot rolling (HR) at $1200^{\circ} \mathrm{C}$ with a reduction ratio of $60 \%$; 
(2) annealing heat treatment (AHT) at $900^{\circ} \mathrm{C}$ for 1 hour in the fcc + bcc two phase region;

(3) cold rolling (CR) at room temperature with a reduction ratio of $75 \%$ to a thickness of $1 \mathrm{~mm}$; subsequently, dog-bone shaped tensile samples with the gauge dimension of $1 \mathrm{~mm} \times 3$ $\mathrm{mm} \times 8 \mathrm{~mm}$ were cut from the cold-rolled sheet;

(4) heat treatment at $1200^{\circ} \mathrm{C}$ for 0.5 hour followed by air cooling (AC) to room temperature; this process was repeated several times in order to induce abnormal grain growth;

(5) solution heat treatment (SHT) at $1200^{\circ} \mathrm{C}$ for $1 \mathrm{~h}$ followed by water quench (WQ);

(6) aging heat treatment (PHT) at $200^{\circ} \mathrm{C}$ for 3 hours to introduce $\mathrm{B} 2$ nano-precipitates followed by water quench.

All heat treatments and air cooling were conducted under high-purity argon atmosphere. Figure 1 shows the illustration of the thermo-mechanical process used to obtain the FeMnAlNi polycrystalline sheets.

The grain size after thermo-mechanical processing was studied by optical microscopy (OM). The etching solution used is composed of $7 \%$ nitric acid and $93 \%$ ethanol by volume. The crystallographic texture in the tension samples after the superelastic tests was examined using electron backscatter diffraction (EBSD) method. EBSD samples were polished using colloidal $\mathrm{SiO}_{2}$ suspension with $0.02 \mu \mathrm{m}$ particle size. The superelastic responses were characterized by isothermal incremental strain tests at room temperature in tension. In these tests, the samples were first loaded to $1 \%$ strain and unloaded, and strain levels were then increased by $1 \%$ during each loading-unloading cycle until failure. The tension tests were conducted with a servo-hydraulic MTS test frame at a strain rate of $5 \times 10^{-4} \mathrm{~s}^{-1}$. The extensometer was directly attached onto the gauge section of the tensile samples. 
The microstructures of the $\mathrm{Fe}_{43.5} \mathrm{Mn}_{34} \mathrm{Al}_{15} \mathrm{Ni}_{7.5}$ polycrystalline alloys following two times air cooling (2AC) and five times air cooling (5AC) down from $1200^{\circ} \mathrm{C}$ are shown in Figure $2 \mathrm{a}$ and $2 \mathrm{~b}$. The OM images were taken at the gauge section of the tensile samples. It can be seen that grain sizes grow continuously with increasing number of air cooling cycles applied to the samples, and very large grains are obtained after 5AC. It should be noted that the fcc second phases forms along the grain boundaries or inside the austenite bcc grains after the air cooling process. The same observation is also reported by Vollmer et al. [21]. Furthermore, it is well known that the fcc second phase is required to introduce abnormal grain growth (AGG) $[21,25]$. However, due to the fact that the fcc second phase does not transform with the matrix, it can reduce the maximum transformation strain during martensitic transformation, and thus, the second phase regions are not desirable. Furthermore, since the fcc second phase is soft and ductile, it can negatively affect the reversibility of the martensitic transformation in the bcc matrix. Thus, in order to remove the second phase regions, the samples were solution heat treated at $1200^{\circ} \mathrm{C}$ for $1 \mathrm{~h}(\mathrm{SHT})$ followed by water quenching (WQ) after the repeated air cooling processes. The average grain size in the two investigated samples is 2 $\mathrm{mm}(\mathrm{d} / \mathrm{t} \sim 0.67)$ for $2 \mathrm{AC}+\mathrm{SHT}$ and $5 \mathrm{~mm}(\mathrm{~d} / \mathrm{t} \sim 1.67)$ for $5 \mathrm{AC}+\mathrm{SHT}$ samples, as shown in Figure $2 \mathrm{c}$ and $2 \mathrm{~d}$, respectively.

Figures $3 \mathrm{a}$ and $3 \mathrm{~b}$ present the tensile stress-strain curves of these samples. The recoverable strain $\left(\varepsilon_{\text {rec }}\right)$ as a function of applied strain $\left(\varepsilon_{\text {applied }}\right)$ from these tests is shown in Figure 3c. Table 1 summarizes the grain size (d) to sample thickness (t) ratio, the critical stress for the onset of martensitic transformation $\left(\sigma_{c}\right)$, fracture stress $\left(\sigma_{f}\right)$, maximum recoverable strain $\left(\varepsilon_{\max }\right)$ and elongation to failure $\left(\varepsilon_{\mathrm{el}}\right)$ of both tensile samples $(2 \mathrm{AC}+\mathrm{SHT}+\mathrm{PHT}$ and $5 \mathrm{AC}+\mathrm{SHT}+\mathrm{PHT})$ after deformation. $\sigma_{\mathrm{c}}$ is high (around $\left.740 \mathrm{MPa}\right)$ in the tension sample $2 \mathrm{AC}+\mathrm{SHT}+\mathrm{PHT}$ with the $\mathrm{d} / \mathrm{t}$ ratio around 0.67 and maximum $\varepsilon_{\max }(1.5 \%)$ 
is small. On the other hand, the $5 \mathrm{AC}+\mathrm{SHT}+\mathrm{PHT}$ sample with the $\mathrm{d} / \mathrm{t}$ ratio about 1.67 exhibits a lower $\sigma_{\mathrm{c}}$ of $420 \mathrm{MPa}$, a larger strain to failure (9\% vs. $4 \%$ ), and higher $\varepsilon_{\max }$ of about $3 \%$.

At least two mechanisms are responsible for these differences. First, the different critical stress levels in the $2 \mathrm{AC}$ and $5 \mathrm{AC}$ samples are related to the activation of differently oriented grains during superelastic transformation. Second, the small grain size leads to greater resistance to the superelastic response with less reversibility due to more significant grain boundary constraints. The smaller average grain size is reflected in the higher $\sigma_{\mathrm{c}}$ and the lower recoverable strain at a given applied strain level in the $2 \mathrm{AC}$ sample. When the grain size becomes large, the grain constraints decreases and each grain can almost be independently transformed to the martensite [17,18]. That means, the elevated grain constraints in the 2AC sample might result in the early fracture of the sample (Fig. 4a), as stresses at grain boundaries become too high. Furthermore, the increased interaction of the martensite plates with the grain boundary likely contributes to the lower fracture strain in the 2AC sample. Clearly, the grain orientation will contribute to grain constraints and resulting reversibility and needs to be addressed in detail.

EBSD analysis was performed on the fractured samples shown in Figure 3. The EBSD orientation map along the rolling direction (RD) and corresponding phase map of the 2AC and 5AC samples are given in Figure $4 \mathrm{a}$ and $4 \mathrm{~b}$, respectively. The smaller grains in the 2AC sample appear to have a preferential alignment along the $\langle 110\rangle$ crystal directions, while the texture of the 5AC sample appears random. In addition to grain size, the crystallographic texture is expected to be a determining factor in the superelastic response of the alloy. Previous single crystal studies $[15,19,20]$ have shown that in a tensile test, the worst superelastic response is observed along the $\langle 100\rangle$ orientations, and reversibility is much improved in tension along the $\langle 110\rangle$ orientations $[9,18,20]$. It is interesting to note that while a random texture was obtained in the FeMAlNi polycrystalline sheet [17], the 
recrystallization texture in the FeMnAlNi wire was along the $\langle 110\rangle$ orientation in the wire axis after the solution heat treatment [18]. In either case, the superelastic response did not differ significantly. In the present study, we also observe large sample-to-sample variation in the texture of both the $2 \mathrm{AC}$ and $5 \mathrm{AC}$ samples, making it difficult to conclude whether a preferential orientation truly exists under the given heat treatment conditions, or if the development of texture has been completed.

Nevertheless, even if a large effect from texture is expected, then it is likely to be beneficial for the reversibility of the superelastic response in the $2 \mathrm{AC}$ sample compared to the $5 \mathrm{AC}$ one since a) the former has a stronger texture, and b) the $\langle 110\rangle$ texture is more favorable for the superelasticity in terms of reversibility. However, this is not the case in the stress-strain curves of Figure 3. A potential reason for this is that the grains with a preferential grain orientation of $\langle 110\rangle$ did not contribute to the overall transformation, due to early failure of the 2AC sample. As such, it is likely that the effect of grain size is much pronounced in this comparison and overcomes the possible effect of texture. This finding is consistent with investigations made by Omori et al. on strong textured wires [18].

Much of the irrecoverable strain shown in the superelastic experiments in Figure 3 can be attributed to retained martensite as shown in Figure 4. In the 2AC sample, the region near the fracture surface remained in the martensite state after failure. In contrast, the 5AC sample reveals two large bands of heavily stabilized martensite that covers parts of austenite grains. Curiously, both of these bands formed in grains with near $<100\rangle$ orientations: one at the boundary between $\langle 100\rangle$ oriented and $\langle 110\rangle$ oriented grains, and another at the boundary between a $\langle 100>$ oriented grain and a near $<111>$ oriented grain. Based on the aforementioned single crystal studies $[15,19,20]$, the $\langle 100\rangle$ orientation shows the worst tensile superelastic reversibility due to the difficulty of activating multiple martensite variants, which may explain the location of the martensite bands. On the other hand, it is 
known that a higher stress is also required to trigger transformation in the $\langle 100\rangle$ oriented crystals in tension. The transformation strains observed in Figure $3 \mathrm{~b}$ are similar to maximum theoretical transformation strain levels in $\langle 100\rangle$ and $\langle 110\rangle$ oriented single crystals, which means it is likely that the majority of the sample experienced transformation during testing, but the reverse transformation is much easier in non- $\langle 100\rangle$ oriented grains. Further study using in situ techniques should be conducted to understand the sequence of transformation in grains of various orientations, and the effect of grain boundary character on the nucleation, propagation, and stabilization of martensite plates.

In summary, the thermo-mechanical processing and effect of microstructure on superelasticity was investigated on the FeMnAlNi polycrystalline sheets. Main conclusions can be listed as follows:

1. The grain size in the FeMnAlNi SMA can be controlled by a cyclic the heat treatment at $1200^{\circ} \mathrm{C}$ for $0.5 \mathrm{~h}$ followed by air cooling to room temperature. Large grain sizes exceeding $5 \mathrm{~mm}$ in the gauge section of tension samples were obtained in the 5 times air cooling procedure.

2. Improved superelastic response is obtained in larger grain size samples, expressed as improved failure strain, reduced critical stress for transformation, and increased recoverable strain.

3. The effect of crystallographic texture on superelastic response appears to be secondary to the effect of grain size when the grain sizes are small $(d / t<1)$.

\section{Acknowledgements}

This work was mainly supported by the National Science Foundation - International Materials Institute Program through the Grant No. DMR 08-44082, Office of Specific 
Programs, Division of Materials Research, Arlington, Virginia. TN thanks Deutsche Forschungsgemeinschaft (DFG) for financial support under grant no. NI1327/-1. 


\section{References}

[1] A. Baruji, T. Kikuchi, S. Kajiwara N. Shinya, Material Science Forum 403 (2002) 394.

[2] S. Kajiwara, T. Kikuchi, Acta Metall. 38 (1990) 847.

[3] A. Sato, E. Chishima, K. Soma, T. Mori, Acta Metall. 30 (1982) 1177.

[4] K. Ando, T. Omori, T. Ohnuma, R. Kainuma, K.Ishida, Appl. Phys. Lett. 95 (2009) 212504.

[5] H. Sehitoglu, X.Y. Zhang, T. Kotil, D. Canadinc, Y. Chumlyakov, H.J. Maier, Metallurgical and Materials Transactions A 33 (2002) 3661.

[6] H. Sehitoglu, I. Karaman, X.Y. Zhang, Y. Chumlyakov, H.J. Maier, Scripta Materialia 44 (2003) 779.

[7] Y. Tanaka, Y. Himuro, R. Kainuma, Y. Sutou, K. Ishida, Science 327 (2010) 1488.

[8] D. Lee, T. Omori, R. Kainuma, Journal of Alloys and Compounds 617 (2014) 120.

[9] T. Omori, S. Abe, Y. Tanaka, D.Y. Lee, K. Ishida, R. Kainuma, Scripta Materialia 69 (2013) 812.

[10] J. Ma, B. Kockar, A. Evirgen, I. Karaman, Z.P. Luo, H. Sehitoglu, C. Efstathiou, H.J. Maier, Y.I. Chumlyakov, Acta Mater 60 (2012) 2186.

[11] J. Ma, B.C. Hornbuckle, I. Karaman, G.B. Thompson, Z.P. Luo, Y.I. Chumlyakov, Acta Mater 61 (2013) 3445.

[12] A. Evirgen, J. Ma, I. Karaman, Z.P. Luo, Y.I. Chumlyakov, Scripta Metall. 67 (2012) 475.

[13] P. Krooß, C. Somsen, T. Niendorf, M. Schaper, I. Karaman, Y.I. Chumlyakov, G. Eggeler, H.J. Maier, Acta Materialia 79 (2014) 126.

[14] Y.I. Chumlyakov, I.K. Kireeva, V.V. Poklonov, Z.V. Pobedennaya, I. Karaman, Technical Physics Letters, 40 (2014) 747.

[15] L.W. Tseng, J. Ma, I. Karaman, S.J. Wang, Y.I. Chumlyakov, Scripta Materialia 101 (2015) 1

[16] Y.I. Chumlyakov, I.V. Kireeva, O.A. Kutz, A.S. Turabi, H.E. Karaca, I. Karaman, Scripta Materialia 119 (2016) 43.

[17] T. Omori, K. Ando, M. Okano, X. Xu, Y. Tanaka, I. Ohnuma, R. Kainuma, K. Ishida, Science, 333 (2011) 68 .

[18] T. Omori, M. Okano, R. Kainuma, APL Materials 1 (2013) 032103.

[19] L.W. Tseng, J. Ma, I. Karaman, S.J. Wang, M. Kaya, Z.P. Luo, Y.I. Chumlyakov, Acta Materialia 89 (2015) 374. 
[20] L.W. Tseng, Ji Ma, B.C.Hornbuckle I. Karaman, G.B. Thompson, Z.P. Luo, Y.I. Chumlyakov, Acta Materialia 97 (2015) 234.

[21] M. Vollmer, C. Segel, P. Krooß, J. Günther, I. Karaman, A. Weidner, H. Biermann, T. Niendorf, Scripta Materialia 108 (2015) 23.

[22] M. Vollmer, P. Krooß, M.J. Kriegel, V. Klemm, C. Somsen, H. Ozcan, I. Karaman, A. Weidner, D. Rafaja, H. Biermann, T. Niendorf, Scripta Materialia 114 (2016) 156160.

[23] L.W. Tseng, Ji. Ma, S. J. Wang, I. Karaman, Y.I. Chumlyakov, Scripta Materialia 116 (2016) 147.

[24] T. Saburi, Ti-Ni shape memory alloys, in: K. Otsuka, C.M. Wayman (Eds.), Shape memory materials, Cambridge University Press, United Kingdom, 1998, pp. 49-94.

[25] T. Omori, H. Iwaizako, R. Kainuma, Materials \& Design 101 (2016) 263-269. 


\section{Figures:}

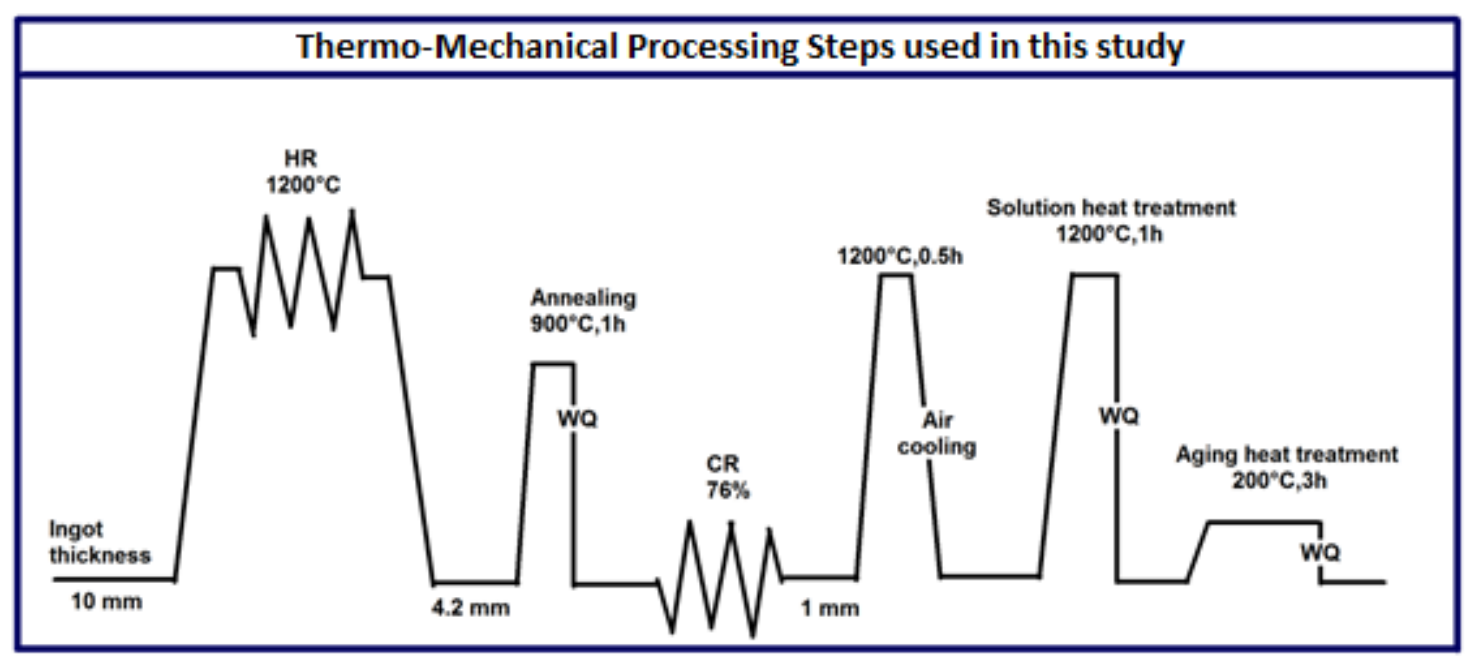

Figure 1. Schematic illustration of the thermo-mechanical processes used in this studey to obtain FeMnAlNi SMA polycrystalline sheets. HR, WQ and CR indicate hot rolling, water quenching and cold rolling, respectively. The solution treatment at $1200^{\circ} \mathrm{C}$ for $0.5 \mathrm{~h}$ was repeated for inducing abnormal grain growth. 


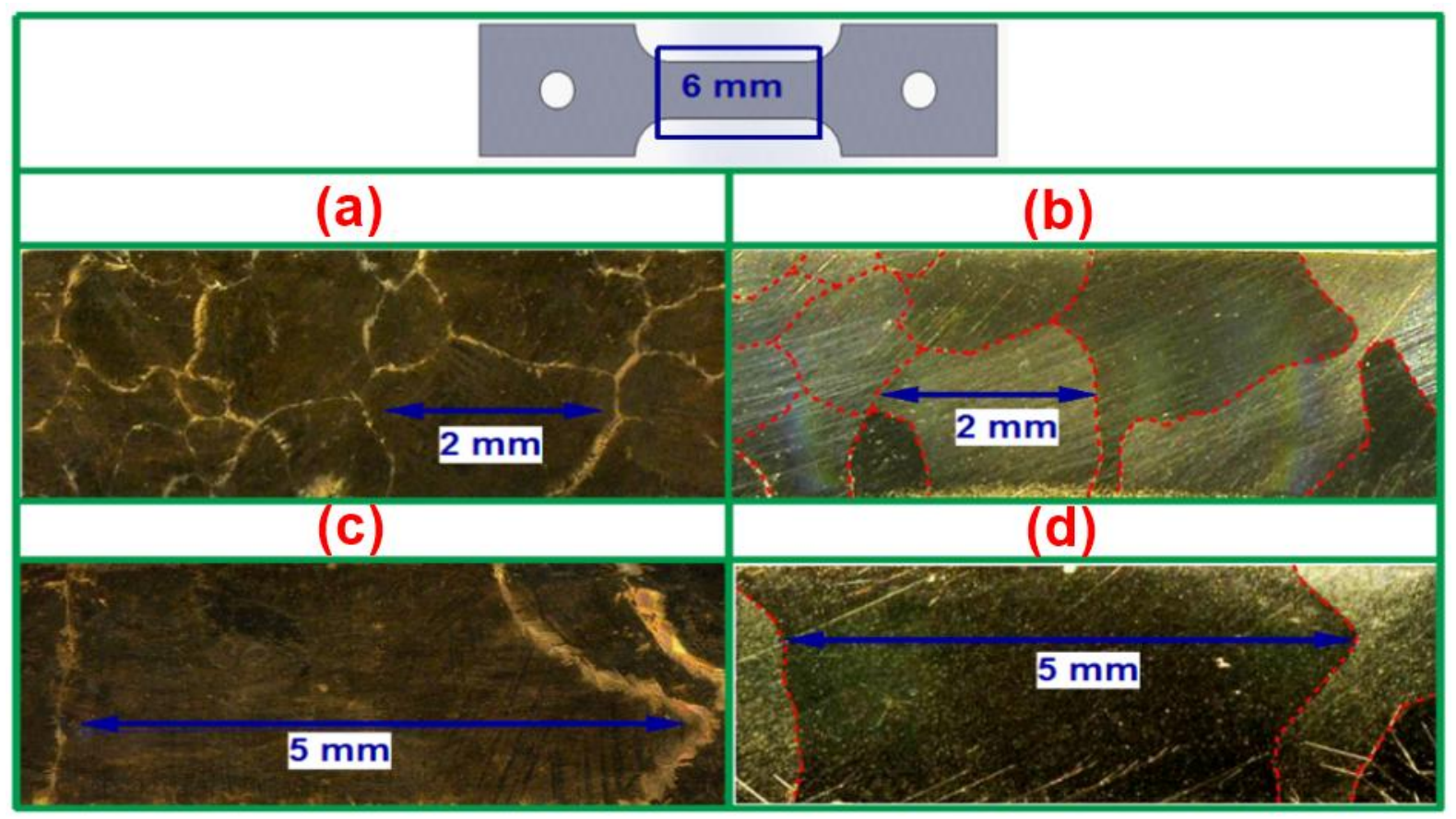

Figure 2. Optical micrographs of the tensile samples upon different thermo-mechanical processes. (a) $\mathrm{HR}+\mathrm{AHT}+\mathrm{CR}+2 \mathrm{AC}$, (b) $\mathrm{HR}+\mathrm{AHT}+\mathrm{CR}+5 \mathrm{AC}$, (c) $2 \mathrm{AC}$ and (d) $5 \mathrm{AC}$ samples after solution treatment at $1200^{\circ} \mathrm{C}$ for 1 hour followed by water quench. HR: Hot Rolling, AHT: Annealing heat treatment; CR: Cold Rolling, AC: Air Cooling. Please refer to Figure 1 for specifics of these treatments. 

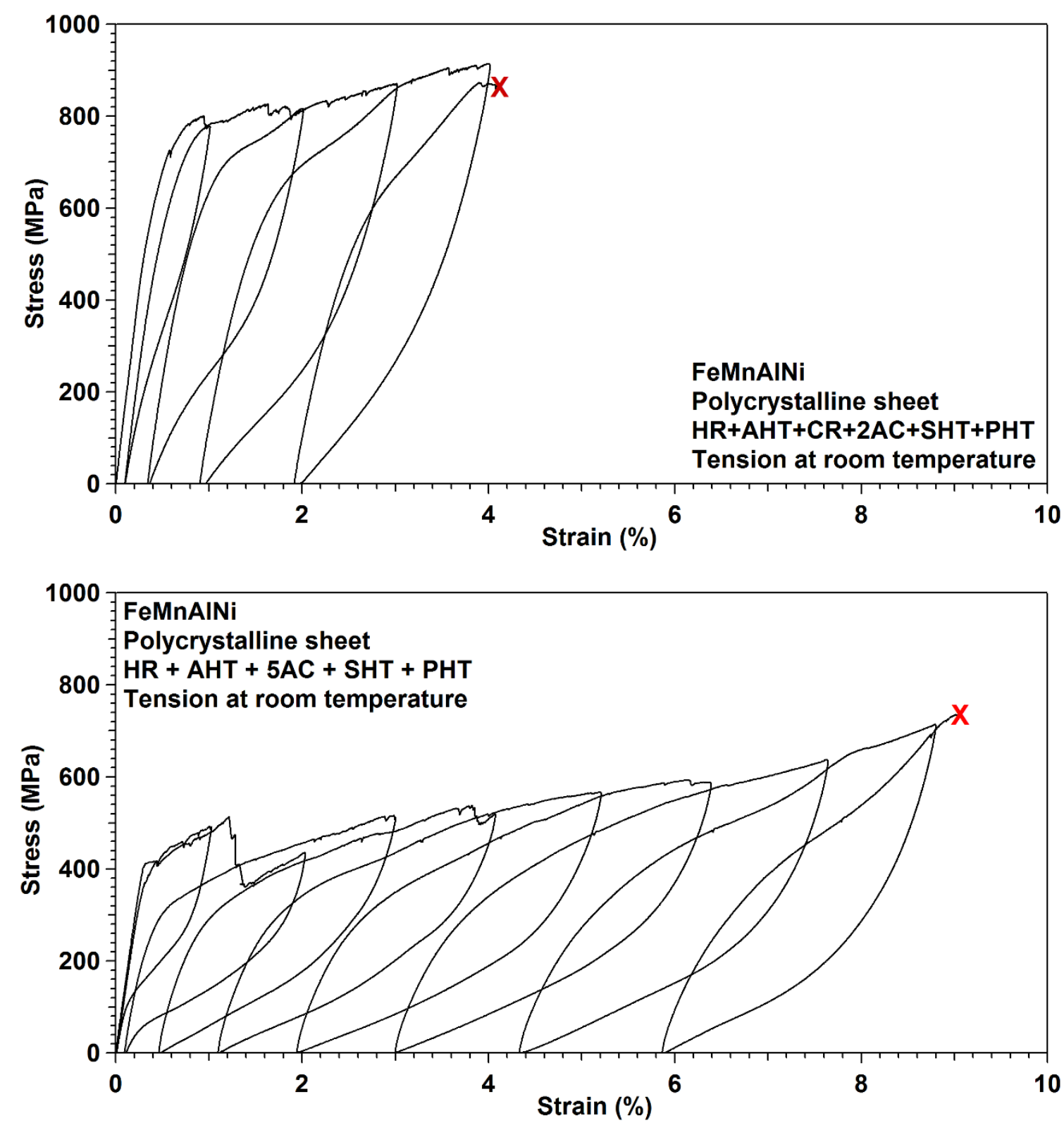


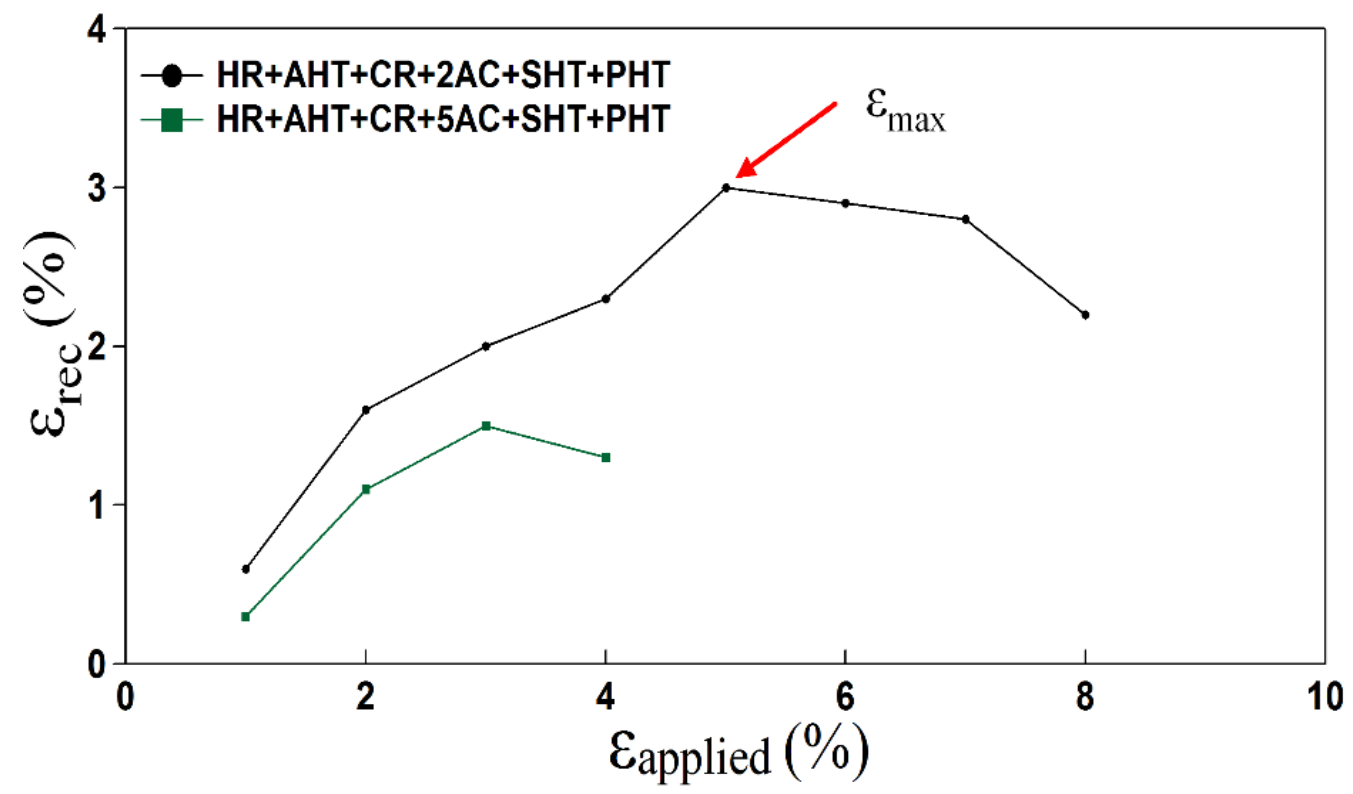

Figure 3. Tensile stress-strain responses of FeMnAlNi polycrystalline sheets upon different thermo-mechanical processes (a) $\mathrm{HR}+\mathrm{AHT}+\mathrm{CR}+2 \mathrm{AC}+\mathrm{SHT}+\mathrm{PHT}$, $\mathrm{HR}+\mathrm{AHT}+\mathrm{CR}+5 \mathrm{AC}+\mathrm{SHT}+\mathrm{PHT}$ and (c) recoverable strain as a function of applied strain. HR: Hot Rolling, AHT: Annealing heat treatment; CR: Cold Rolling, AC: Air Cooling, SHT: Solution Heat Treatment, PHT: Precipitation Heat Treatment. Please refer to Figure 1 for specifics of these treatments. 


\section{(a) $\mathrm{HR}+\mathrm{AHT}+\mathrm{CR}+2 \mathrm{AC}+\mathrm{SHT}+\mathrm{PHT}$ after deformation}

\section{IPF map}

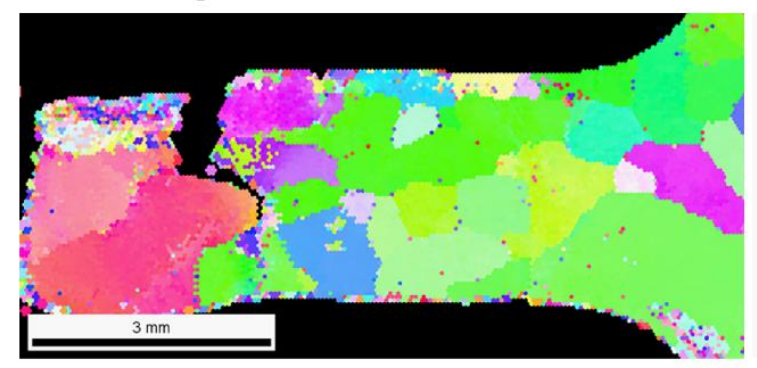

\section{Phase map}

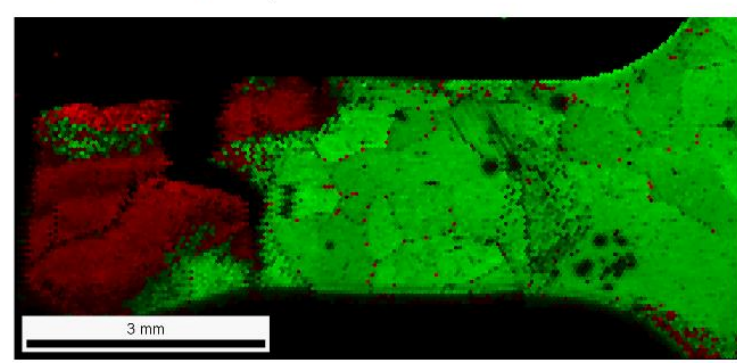

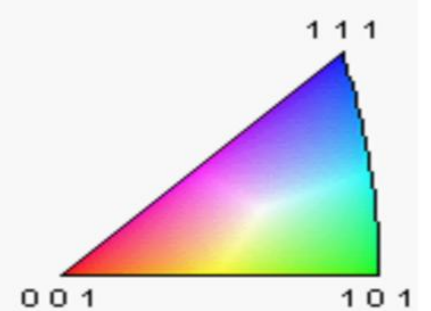

TD

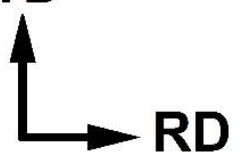

Austenite

Martensite

(b) $\mathrm{HR}+\mathrm{AHT}+\mathrm{CR}+5 \mathrm{AC}+\mathrm{SHT}+\mathrm{PHT}$ after deformation

\section{IPF map}

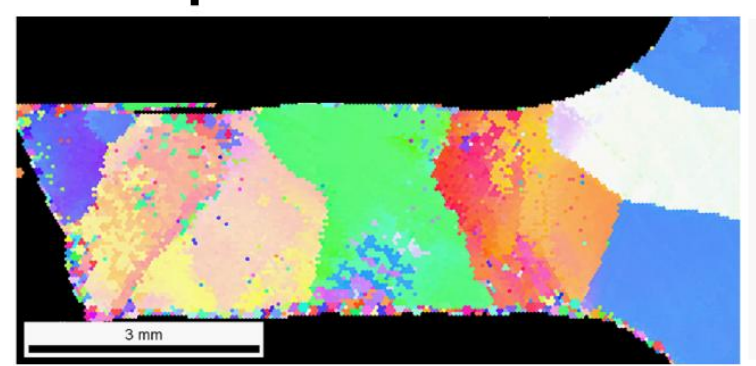

\section{Phase map}

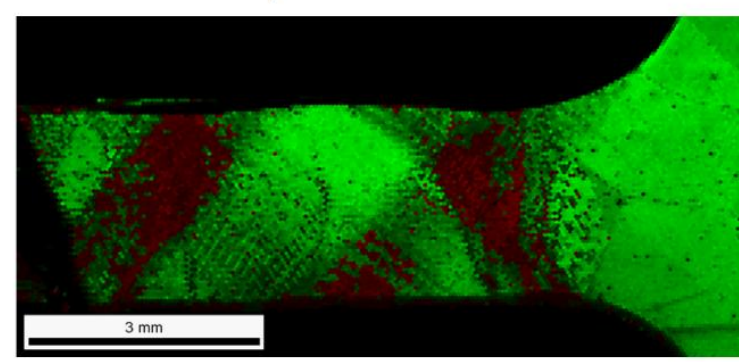

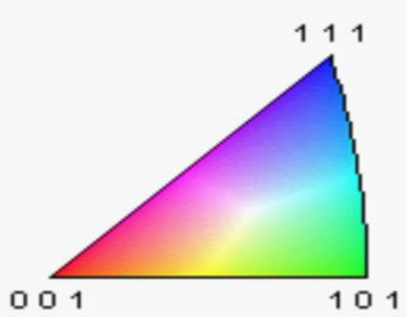

TD

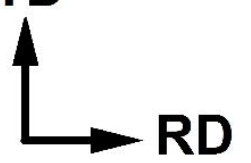

Austenite

Martensite

Figure 4. Inverse Pole Figure (IPF) mapping and phase mapping of FeMnAlNi polycrystalline sheet upon different thermo-mechanical processes after deformation. (a) $\mathrm{HR}+\mathrm{AHT}+\mathrm{CR}+2 \mathrm{AC}+\mathrm{SHT}+\mathrm{PHT}$ and (b) $\mathrm{HR}+\mathrm{AHT}+\mathrm{CR}+5 \mathrm{AC}+\mathrm{SHT}+\mathrm{PHT}$. 
Table 1. Grain size (d) to sample thickness (t) ratio, critical stress for the onset of martensitic transformation $\left(\sigma_{\mathrm{c}}\right)$, fracture stress $\left(\sigma_{\mathrm{f}}\right)$, superelastic strain $\left(\varepsilon_{\mathrm{SE}}\right)$, tensile elongation $\left(\varepsilon_{\mathrm{el}}\right)$ in the FeMnAlNi polycrystalline samples.

\begin{tabular}{cccccc}
\hline Sample conditions & $\mathbf{d} / \mathbf{t}$ & $\boldsymbol{\sigma}_{\mathbf{c}}(\mathrm{MPa})$ & $\boldsymbol{\sigma}_{\mathrm{F}}(\mathrm{MPa})$ & $\boldsymbol{\varepsilon}_{\max }(\%)$ & $\boldsymbol{\varepsilon}_{\mathrm{el}}(\%)$ \\
\hline HR+AHT+CR+2AC+SHT+PHT & 0.67 & 730 & 890 & 1.5 & 4 \\
HR+AHT+CR+5AC+SHT+PHT & 1.67 & 420 & 730 & 3 & 9 \\
\hline
\end{tabular}




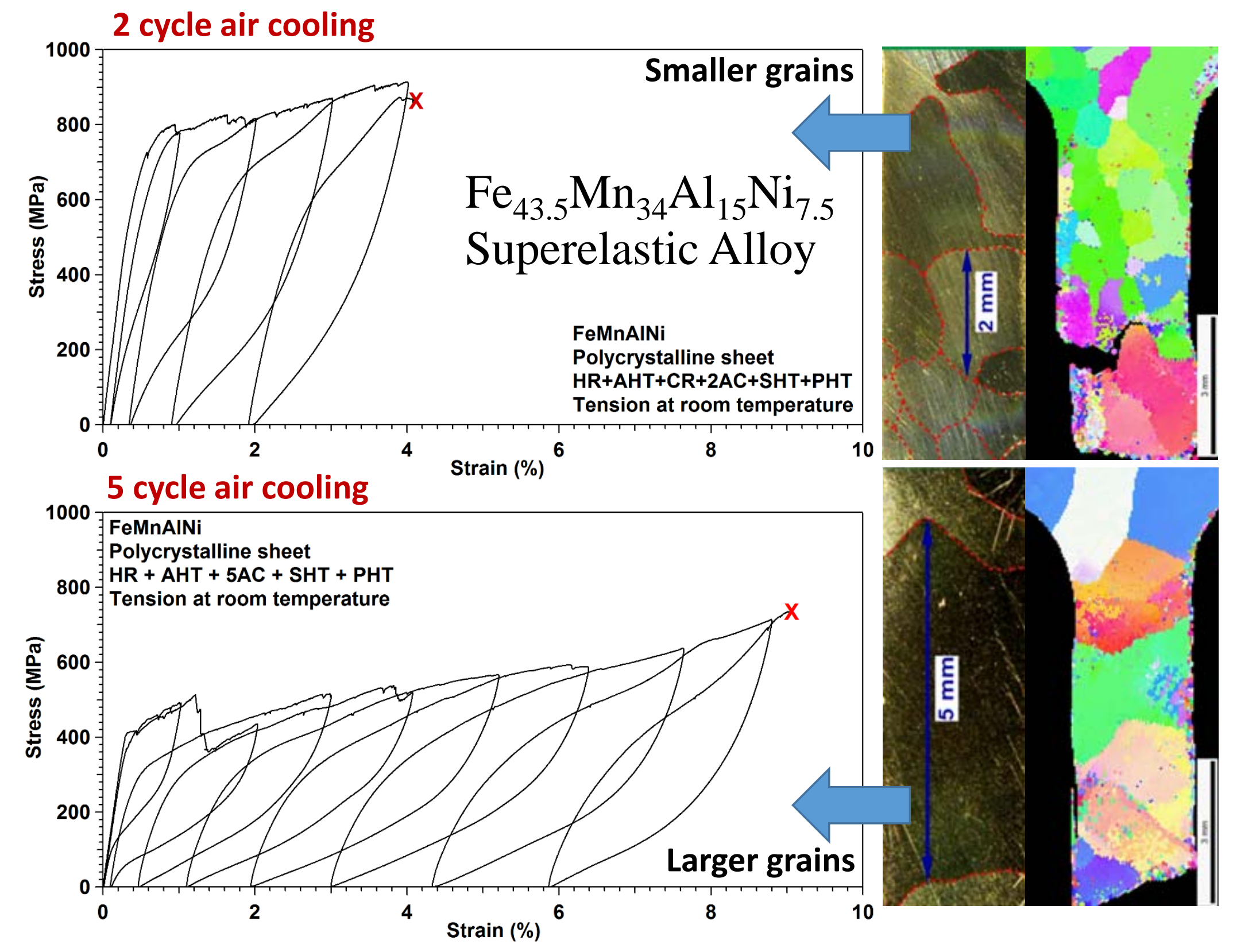

